\title{
Theoretical justification of fruit separation rolling process by a planetary fruit separator
}

\author{
Victor A. Ablikov ${ }^{1, *}$, Yuri K. Castidi ${ }^{1}$, and Daria M. Klinova ${ }^{1}$ \\ ${ }^{1}$ FSBEI HE Kuban State Agrarian University named after I.T.Trubilin, Krasnodar, Russian Federation
}

\begin{abstract}
The article is devoted to the theoretical justification of the process of rolling stems by planetary rollers of the fruit separator in the harvesting of Solanaceae vegetables as reusable as at direct full harvest. The article has a theoretical, research character, expressed in the fact that the issue of Solanaceae vegetables harvesting was theoretically considered, the analysis of methods and means for the introduction of dry inorganic substances was given, when considering the process of rolling stems of Solanaceae vegetables as a rolling of elastic-plastic material there were obtained the dependences that determine the kinematic and energy parameters of planetary multi-rolling fruit separators. The conclusions set out the main results achieved so far. The type of the proposed design was theoretically justified, its description and the flow of the technological process were given. As a result of the work done, the process of fruit removal from a plant with offered working elements was shown.
\end{abstract}

The researches in the field of Solanaceae vegetables harvesting are conducted in Kuban State Agrarian University at the department of "Processes and machines in agribusiness". The work is aimed at the development of working elements of rotor type for reusable harvesting of Solanaceae vegetables. It is probable, that the present construction allows to improve the qualitative rates of working elements of fruit separators.

During the movement of the fruit separator, located at an angle $\alpha$ to the direction of movement, the fruit mass is rolled by rollers. At the same time, the process of fruit removal is carried out due to two types of deformation of the plant - pulling (vibration) of the bush's stems and combing the fruits. Only large fruits are separated, the size of which is greater than the gap in the working slit. The fruit will be separated if the force of the action of the roller exceeds the force of connection with the peduncle. Small fruits, ovaries and flowers remain on the plant in the field and continue to grow [1].

The technological operation of rolling the stems of the plant's bush with planetary rollers is one of the main, providing the combing of the fruits from the bush.

The input parameters here are the output parameters of the technological operation of the first level, and the criterion for assessing the quality is $-\varepsilon_{\text {пов }}-$ the degree of damage to the stems of the plant, which should strive for a minimum value [2].

\footnotetext{
${ }^{*}$ Corresponding author: sergey belousov87@mail.ru
} 
Let us consider the technological process of rolling stems by the planetary multi-shaft apparatus (Figure 1). The number of rolls on the drum of the planetary apparatus of $K_{\mathrm{T}}$ by V. V. Derevenko is determined by the formula for the two-drum apparatus [3]:

$$
\mathrm{K}_{\mathrm{T}}=\frac{\pi}{\mathrm{a}+\lambda_{\mathrm{r} 2}+\sin \alpha}
$$

where $\alpha$ - central angle determining the position of initial and final points of contact of rollers with stems;

$\lambda_{\mathrm{c} 2}$ - relation of circumferential speed of the drum 2 to the speed of the stem's pulling,

$$
\lambda_{\mathrm{c} 2}=\frac{\square_{2}}{W_{\mathrm{c}}}
$$

for single drum apparatus

$$
\mathrm{K}_{\mathrm{T}}=\frac{\pi}{\mathrm{a}+\mathrm{z} \beta}
$$

where $\alpha$ and $\beta$ - central angles on planetary and cylindric drums defining the point of initial and final positions of a roller on the stem;

$\varepsilon=\frac{\mathbb{W}_{2}}{\mathbb{W}_{1}}$ - relation of speeds of rotation of cylindrical and planetary drums.

We should take $K_{\mathrm{T}}=6 \div 9$ units for two-drum apparatus, for single drum $-\varepsilon=\frac{1}{\mathbb{a}} \div \frac{1}{6}$ and $\mathrm{K}_{\mathrm{T}}=6 \div 10$ units.

If the number of $K_{\mathrm{T}}$ rolls to take more than it can be obtained by formulas (1) and (3), this ratio will be called the overlap coefficient [4].

The angle speeds of planetary drums from the formulas (4) and (5) are as follows:

For two-drum apparatus:

$$
\omega_{2}=\frac{\mathbb{V}_{\varepsilon}}{r_{2} \cdot \sin \alpha} \cdot\left(\eta \frac{\pi}{\mathbb{R}}-\alpha\right),
$$

For single drum

$$
\omega_{2}=\frac{\mathbb{E}_{1}}{\beta} \cdot\left(\eta \frac{\bar{Z}}{\mathbb{K}}-\alpha\right)
$$

Condition of stem's rolling in a working slit

$$
\mathrm{Q}_{\mathrm{c}}+\Sigma \mathrm{T}_{\mathrm{x}}-\Sigma \mathrm{N}_{\mathrm{x}} \geq 0
$$

where $\mathrm{Q}_{\mathrm{c}}$ - effort of stems' rolling from apparatus's motion;

$\Sigma \mathrm{T}_{\mathrm{X}}$ and $\Sigma \mathrm{N}_{\mathrm{X}} \sim$ sum of projections of forces of normal pressure from the side of rollers 3 and 4 rolling the stems and forces of friction to the motion of the stems.

$$
\begin{array}{r}
\sum \mathrm{N}_{\mathrm{x}}=\mathrm{N}_{\mathrm{x} 3}+\mathrm{N}_{\mathrm{x} 4}, \\
\sum \mathrm{T}_{\mathrm{x}}=\mathrm{T}_{\mathrm{x} 3}+\mathrm{T}_{\mathrm{x} 4}
\end{array}
$$

To determine the forces $\mathrm{N}_{\mathrm{x} 3}, \mathrm{~T}_{\mathrm{x}}, \mathrm{N}_{\mathrm{x} 4}$, and $\mathrm{T}_{\mathrm{x} 4}$, we use the assumption of a professor I.V. Kragelsky about even distribution of normal pressures $\mathrm{q}_{3}$ and $\mathrm{q}_{4}$ for points of rollers' contacts with a stem taken which was when studying the collapse of bast crops [5]. 

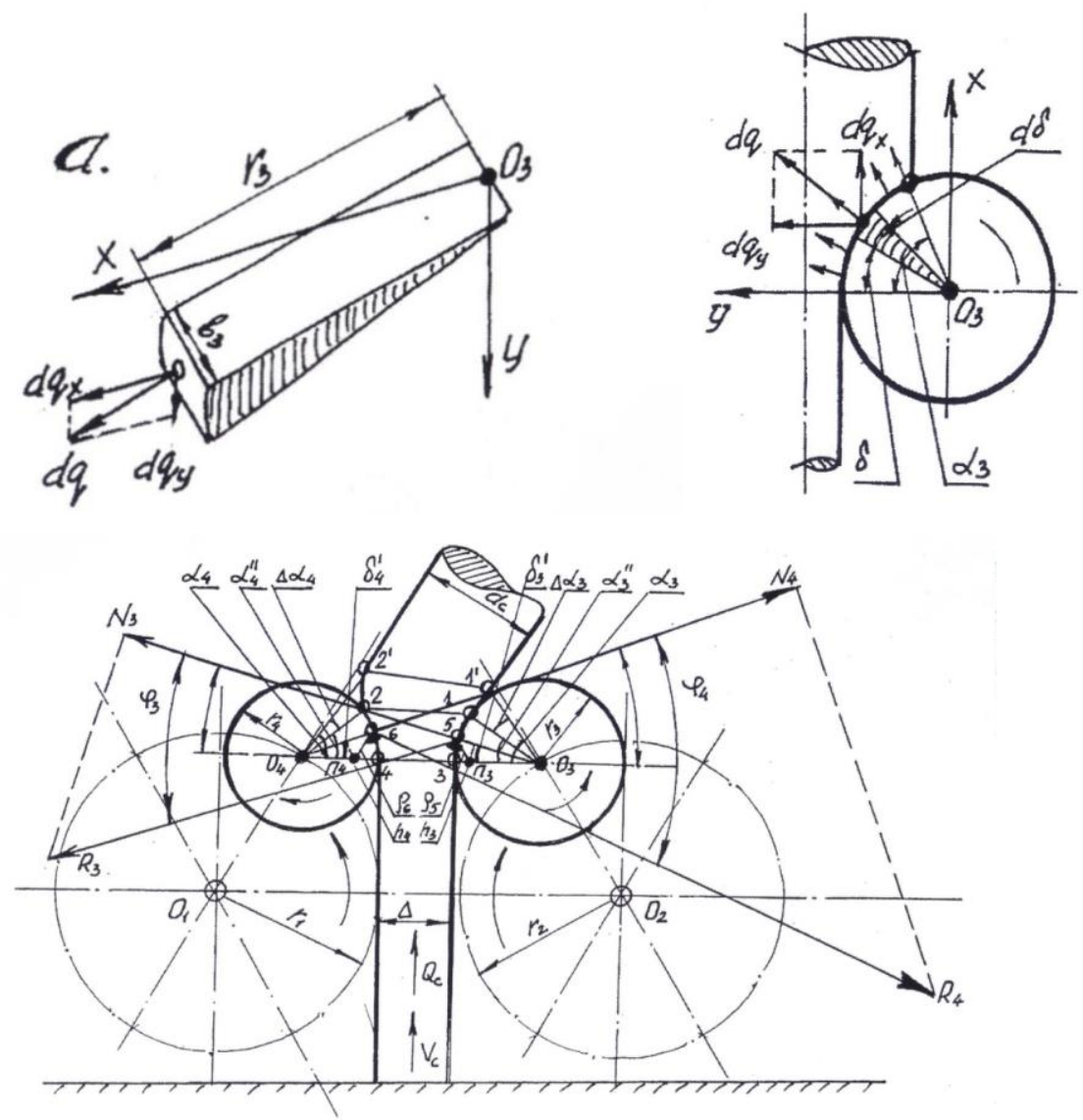

Fig. 1. Rolling of stems by planetary rollers.

If the elementary force is (Figure 1a)

$$
\begin{gathered}
\mathrm{dq}_{3}=\mathrm{q}_{3} \mathrm{~b}_{3} \mathrm{r}_{3} \mathrm{~d} \delta, \\
\mathrm{dq}_{4}=\mathrm{q}_{4} \mathrm{~b}_{4} \mathrm{r}_{4} \mathrm{~d} \delta,
\end{gathered}
$$

where $r_{3}$ and $r_{4}$ - radii of circumferences of rollers 3 and 4 ; $b_{3}$ and $b_{4}$ - width of stem's contact area with rollers.

Projections of elementary forces on the axis $\mathrm{X}$ and $\mathrm{Y}$ are equal:

$\mathrm{dq}_{3 \mathrm{x}}=\mathrm{dq}_{3^{*}} \cos \delta \mathrm{dq}_{3 \mathrm{y}}=\mathrm{dq}_{3^{*}} \sin \delta$

$$
\mathrm{dq}_{4 \mathrm{x}}=\mathrm{dq}_{4^{3}} \cos \delta \mathrm{dq}_{4 \mathrm{y}}=\mathrm{dq}_{4^{3}} \sin \delta
$$

In the course of integrated expressions (8) and (9) on $\alpha$ in limits from 0 to $\mathrm{a}_{3}$ and from 0 to $\mathrm{a}_{4}$ we obtain

$$
\begin{aligned}
& \mathrm{Q}_{3 \mathrm{x}}=\int_{0}^{\mathbb{Q}_{3}} d q_{\mathrm{Ag}}=\mathrm{q}_{3} \mathrm{~b}_{3} \mathrm{r}_{3^{3}}\left(1-\cos \alpha_{\mathbb{A}}^{\llbracket p}\right), \\
& \mathrm{Q}_{3 \mathrm{y}}=\int_{0}^{\mathrm{N}_{3}} d q_{\mathrm{ay}}=\mathrm{q}_{3} \mathrm{~b}_{3} \mathrm{r}_{3^{3}} \sin \kappa_{\mathrm{a}}^{\square} ; \\
& \mathrm{Q}_{4 \mathrm{x}}=\int_{0}^{\alpha_{3}} d q_{4 x}=\mathrm{q}_{4} \mathrm{~b}_{4} \mathrm{r}_{4} \mathrm{x}\left(1-\cos \kappa_{4}^{a p}\right),
\end{aligned}
$$




$$
\mathrm{Q}_{4 \mathrm{y}}=\int_{0}^{x_{3}} d q_{4 y}=\mathrm{q}_{4} \mathrm{~b}_{4} \mathrm{r}_{4}{ }^{3} \sin \alpha_{4}^{5 y}
$$

where $\alpha_{\pi}^{* 8}$ and $\alpha_{4}^{a s}$ - angles of rollers' coverage,

$\alpha_{a}^{a v}=\mu \alpha_{3}, \quad \alpha_{4}^{a s}=\mu \alpha_{4} \mu$ - coefficient of reduction of angles $\alpha_{3}$ and $\alpha_{4}$ taking into account the crumpling of a rolled stem before rollers due to its elasticity $\mu=0,76$.

From conditions of a stem's balance $Q_{3 y}=Q_{4 y}$. by the axis $Y$ and balance $\frac{q_{3}}{q_{4}}=\frac{b_{4}}{b_{3}}$ :

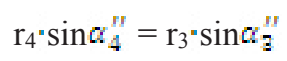

taking the expression (12) from trapezium $0_{3} 120_{4}$, we obtain after transformations

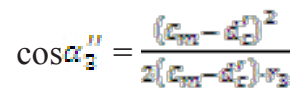

where $C_{m}$ - distance between centers of rollers 3 and 4 ,

$$
\mathrm{C}_{\mathrm{m}}=\mathrm{r}_{3}+\mathrm{r}_{4}+\Delta,
$$

$d_{\text {e. }}^{0}$ - thickness of a stem gripped by rollers 3 and 4 in the input of a working slit is determined in dependence on diameter of a stem $\mathrm{d}_{\mathrm{c}}$ and relation $\frac{v_{3}}{r_{4}} ; \Delta$ - gap between rollers 3 and 4 .

Substitute for $\mathrm{N}_{3}=\sqrt{Q_{\mathrm{ax}}^{2}+Q_{\mathrm{ay}}^{2}}$ and $\mathrm{N}_{4}=\sqrt{Q_{4 \mathrm{x}}^{2}+Q_{4 y}^{2}}$ from expressions (10) and (11), we obtain the value of forces $\mathrm{R}_{3}$ and $\mathrm{R}_{4}$ after transformations [6]:

$$
\begin{gathered}
\mathrm{R}_{3}=\mathrm{N}_{3} \sqrt{1+f_{a}^{2}}=2 \mathrm{q}_{3} \mathrm{~b}_{3} \mathrm{r}_{3}=\frac{a_{3}^{g}}{2} \sqrt{1+f_{a}^{2}}, \\
\mathrm{R}_{4}=\mathrm{N}_{4} \sqrt{1+f_{4}^{2}}=2 \mathrm{q}_{4} \mathrm{~b}_{4} \mathrm{r}_{4}=\frac{\mathrm{a}_{4}^{F}}{2} \sqrt{1+f_{4}^{2}}
\end{gathered}
$$

where $f_{3}$ and $f_{4}$ - coefficients of rollers $s$ and 4' friction by stems. Application points of forces $R_{3}$ and $R_{4}$ are defined by values of angles $\delta_{a}^{0}$ and $\delta_{4}^{s}$

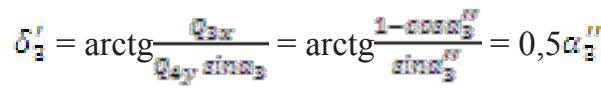

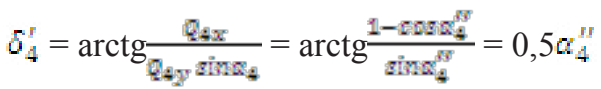

If we accept that

$$
\kappa_{a}^{\star s p}=0,76 \mathrm{a}_{3} \quad \text { and } \quad \kappa_{4}^{\llbracket s}=0,76 \mathrm{a}_{4}
$$

It will be $\delta_{a}^{s}=0,38 \mathrm{a}_{3} \quad$ and $\quad \delta_{4}^{s}=0,38 \mathrm{a}_{4}$

Due to N.M. Nikolaev $\delta^{\prime}=(0,22 \div 0,39) \alpha$.

Moments of forces $R_{3}$ and $R_{4}$ relative to the instantaneous axes of rotation of the rollers 3 and 4 will be equal to: $M_{3}=R_{3} \rho_{5}$.

$$
\mathrm{M}_{4}=\mathrm{R}_{4} \rho_{6}
$$

where $\rho_{5}, \rho_{6}-$ according to arms of forces $R_{3}$ and $R_{4}$. 
Values $\rho_{5}$ and $\rho_{6}$ (Figure 1) are determined from triangles $\Pi_{3} 0_{3} 5$ and $\Pi_{4} \mathrm{O}_{4} 6$ :

$$
\begin{aligned}
& \rho_{5}=\frac{x_{3}}{\lambda_{c 3}} \sqrt{\lambda_{c a}^{2}+1-2 \lambda_{c a} \cdot \cos \delta_{a}^{9}}, \\
& \rho_{6}=\frac{x_{4}}{\lambda_{c 4}} \sqrt{\lambda_{c 4}^{2}+1-2 \lambda_{c 4} \cdot \cos \delta_{4}^{9}}
\end{aligned}
$$

Power $\mathrm{W}_{\mathrm{c}}$ needed for stems' rolling by two-drum apparatus:

$$
\mathrm{W}_{\mathrm{c}}=\mathrm{e}_{\mathrm{c}}\left[\mathrm{M}_{3}\left(\omega_{3}-\omega_{2}\right)+\mathrm{M}_{4}\left(\omega_{4}-\omega_{1}\right)\right] \text {, }
$$

where $e_{c}$ - amount of stems which are in a working slit simultaneously;

$$
\mathrm{e}_{\mathrm{c}}=\frac{\operatorname{LnsVR}}{\operatorname{agove}}
$$

where L- average length of stem; $\mathrm{m}$ - amount of stems on 1ha; B - width of a harvester's coverage; $\mathrm{V}_{\mathrm{K}^{-}}$speed of a harvester; $\mathrm{V}_{\mathrm{c}^{-}}$speed of stem's motion in a working slit; $\mathrm{M}_{3}$ and $\mathrm{M}_{4}-$ moments of appropriate equal forces $\mathrm{N}$ and $\mathrm{T}$ relative to the instantaneous axis of rotation $[7,10]$.

Thus, when considering the process of rolling Solanaceae vegetables stems as a rolling of elastic-plastic material, there were obtained the dependences that determined the kinematic and energy parameters of planetary multi-roller fruit separators $[8,9]$.

\section{References}

1. Trubilin E.I. Results of experimental studies determining the degree of traction resistance of the plowshoe in the treatment of heavy soils / Trubilin E.I., Belousov S.V., Lepshina A.I. // The Political Network Electronic Scientific Journal of the Kuban State Agrarian University. -2014. -No. 103.-C. 673-686.

2. E.I. Trubilin. Economic efficiency of the dump cultivation of soil developed by a combined plowshoe / Trubilin E.I., Belousov S.V., Lepshina A.I. // The political network electronic scientific journal of the Kuban State Agrarian University. -2014. No. 103.-C. 654-672.

3. E.I. Trubilin. The main soil cultivation with the formation turnover in modern working conditions and devices for its implementation / Trubilin E.I., Belousov S.V., Lepshina A.I. // The political network electronic scientific journal of the Kuban State Agrarian University. -2014. - No. 104.-C. 1902-1922.

4. Belousov S.V. Communication of science and technology in the field of development of machines for the basic tillage of the soil with the circulation of the bed / Belousov S.V. // The political network electronic scientific journal of the Kuban State Agrarian University. -2015. No. 109.-C. 468-486.

5. Belousov S.V. Modern technologies of soil cultivation / Belousov S.V. // Scientific provision of the agro industrial complex. -2012. -FROM. 3-4.

6. Parkhomenko G.G. Perfection of working organs for tillage / Parkhomenko GG, Bozhko I.V., Semenikhina Y.A., Pantyukhov I.V., Drozdov S.V., Gromakov A.V., Kambulov S.I., Belousov S.V. // State and prospects of the development of agricultural machinery. Collection of articles of the 9th international scientific and practical conference within the framework of the 19th international agro-industrial exhibition "Interagro-mash-2016". -2016. -FROM. 27-30.

7. Belousov S.V. Development of the construction of a plow for the treatment of heavy soils / Belousov S.V., Trubilin E.I. // Science of the Kuban. -2013. -No 1.-C. 37-40. 
8. Belousov S.V. Patent search for structures that provide soil treatment with the turnover of the reservoir. Search method. The proposed technical solution / Belousov S.V. // The political network electronic scientific journal of the Kuban State Agrarian University. -2015. No. 109.-C. 416-450.

9. Belousov S.V. Decrease in energy intensity of the process of basic processing of soil with turnover of the bed / Belousov S.V. // Fundamental foundations of modern agrarian technologies and technology. Collection of works of the All-Russian Youth Scientific and Practical Conference. -National Research Tomsk Polytechnic University. -2015. -FROM. 280-283.

10. Belousov S.V. Role and prospects for the development of small-scale mechanization in the context of co-temporary engineering / Belousov S.V. / Scientific support of the agro-industrial complex. A collection of articles on the materials of the 72nd Scientific and Practical Conference of pre-applicants on the results of research work for 2016 2017.-C. 277-278. 